\title{
Medical Student Reflects on Hospice Experience
}

\author{
Brian L. Baker and Jennifer M. Joyce, MD
}

Mrs. Smith, an 84-year-old woman, was admitted to Hospice of the Bluegrass, Lexington, Ky, after she had an emergency appendectomy that was complicated by fecal peritonitis. She originally visited a local emergency department with complaints of nausea, vomiting, and diffuse abdominal pain. The emergency physician suspected peritonitis, but Mrs. Smith refused surgery, and her condition was treated empirically with metronidazole and levofloxacin. She later developed septicemia and consented to an exploratory laparotomy. An emergency appendectomy was performed, and she returned home after a difficult rehabilitation. Her recovery progressed fairly well for several weeks, with the exception of gradually worsening and unresponsive diarrhea that eventually tested positive for Clostridium difficile. She again developed septicemia, and a computed tomogram showed a diverticular abscess. She continued to refuse any nonpharmacologic treatment, including percutaneous abscess drainage. It was during this time that her condition was believed to be terminal, and she was referred to hospice.

I came to know Mrs. Smith during the first week of my family practice clerkship, when I visited her home with Laura, a hospice nurse. As I entered the assisted-living apartment, I first noticed the cleanliness and organization of her dwelling. The bookshelves lining her walls were full of novels and collectibles. She was sitting in her recliner and turned eagerly to greet her visitors. She was cordial and inquired about my training. Mrs. Smith was the first hospice patient I had encountered, and I was surprised at her appearance of relative wellness. I was unaware of her medical conditions at that time, but as I listened, I began to piece together her story.

Submitted 18 September 2002.

From the College of Medicine (BLB), and the Department of Family Practice (JMJ), University of Kentucky, Lexington. Requests for reprints should be addressed to Brian L. Baker, Chandler Medical Center, 800 Rose St, Box 253, Lexington, KY 40536.
The conversation between Mrs. Smith and Laura was at times marked by conflict. During my first visit, Mrs. Smith was contemplating whether to proceed with percutaneous abscess drainage or to continue conservative management. I learned that although her condition improved with intravenous metronidazole and fluids, after the antibiotic was discontinued, the miserable illness returned in a nearly identical fashion. Although I thought Laura explained the circumstances of Mrs. Smith's condition clearly, the patient seemed not to understand her illness or its treatment. If only she would agree to a procedure, her primary disorder could be cured. I felt obligated at least to try to help Mrs. Smith make what I considered to be the right decision.

Unsure of my role, I limited my involvement to listening and answering medical questions during the first encounter. This posture seemed completely inadequate to me, but I knew so little about Mrs. Smith's emotional and social circumstances that any further participation would have been presumptuous. The patient's confusion intrigued me, and the potential to help someone excited me. Despite Laura's impression that this patient was not the best choice for my project because of her reluctance to speak of past events, I concluded that the possible benefit to both the patient and me outweighed the risk of an unsuccessful interview.

I described myself as a student in need of a favor. I told her I needed to create a family tree for one of the hospice patients I had seen, and she seemed to be very pleasant and approachable. Fortunately, a little flattery went a long way. The subsequent discussion led to one of the most powerful experiences I have had as a medical student.

Mrs. Smith remarked to me that "people in Oregon are lucky because they have doctor-assisted suicide." She stated that without any living descendants, she felt that she has no reason to live. Her only relatives were her sister and sister's family, who also lived in Lexington. This relationship brought Mrs. Smith to Kentucky when she was 75 
years old, after her daughter's sudden and unexpected death caused by bronchospasm. This dominant event in her life makes the month of June particularly difficult, because it marks the anniversary of both her daughter's birth and death. She was stoical as we spoke about the loss, stating, "I have had a beautiful life and a tragic life."

She went on to relate her father's suicide when he was 89 years old, and her husband's death of carbon monoxide poisoning while working in their garage on their ninth wedding anniversary. With no financial resources and a 4-year-old daughter, she found a job for the first time and lived her life day by day. Mrs. Smith spoke proudly of her work ethic and ability to provide for herself. After three visits, I concluded that she genuinely seemed at peace with dying. She once remarked, "I want to enjoy what time I have left." I think this wish was her reason for refusing surgical treatment. The complications and rehabilitation that resulted from her last surgery were too great for her to justify the time a medical procedure could add to her life.

I was most impressed by Mrs. Smith's mental strength and ability to cope with hardships. When I asked about the source of this strength, her facial expression was both proud and resentful. She said, "I am just a strong person, I guess." Grieving for her daughter, in addition to the progressive pain and difficulty walking caused by her osteoarthritis and a stroke, prevented Mrs. Smith from establishing new social connections outside her family. She was no longer able to do her own grocery shopping and was largely confined to her apartment. Her previous losses might also have caused her to avoid new relationships for fear of further loss. After she was released from the hospital, she frequently stated that she would have preferred to die during surgery instead of living with recurrent bouts of diarrhea and sepsis. I sensed that she struggled with acceptance of her impending death because of her fluctuating condition. How could she truly accept dying if she had reasonable expectations of recovery?

As with many homebound patients, Mrs. Smith's hospice nurse and social worker became important parts of her community. Their regular visits doubled the number of persons with whom she communicated. A sitter used by her assisted-living apartment complex also provided important daily interaction. Interestingly, her physician did not seem to be a source of support, which might be related to the number of specialists involved in her care.

In our conversations, Mrs. Smith never indicated a generalized distrust of physicians; however, it is clear that she made her own decisions based on available information. In her opinion, the physician is neither always right nor always wrong. Mrs. Smith was quite eager at the time of my first visit to enroll in a research study of a new antibiotic directed at $C$ difficile. She was optimistic that the experimental drug might cure her illness and was disappointed and argumentative when Laura explained that this outcome was not anticipated because of the abscess.

Mrs. Smith claimed her strong relationship with God helped her deal with the misfortunes of her life. She did not view her illness or the tragedies of her life as punishment for sin. Her ability to comprehend complex ideas and her relatively high socioeconomic status helped her cope with illnesses and insults. I imagine that Mrs. Smith's age also gave her strength in times of stress. Her generation endured two world wars and the Great Depression, all which must have instilled a resilience not acquired by later age-groups.

After meeting Mrs. Smith, my goal was simply to make her treatment options more understandable. I made four index cards outlining the four possible treatment options and their risks and benefits. These options included no treatment, drainage of the abscess, treatment with short-term metronidazole, and treatment with long-term metronidazole. I believed that after reviewing these cards, she would be more likely to choose curative drainage of the abscess. At the very least, I would feel comfortable that she had made a fully informed decision. When Mrs. Smith read the cards, she immediately discarded the no treatment option. She also was unsatisfied with medical therapy because the condition would not be cured; yet, she continued to refuse a drainage procedure. After reading the cards several more times, she indicated that drainage might indeed be the best option, and I believed that my approach had been truly successful. On returning to the home 1 week later, however, I learned that her physician disallowed this route because Mrs. Smith had given consent in the past, only to reconsider at the last minute. Instead, the plan was to take metronidazole indefinitely.

When I last spoke with Laura, she anticipated that Mrs. Smith would be discharged from hospice. 
I was concerned that the loss of regular visits from the hospice team would remove an important source of psychological support and community interaction. A comprehensive discharge plan that included ways to meet her psychosocial needs would help alleviate this concern.

I learned a great deal about myself through this experience. One realization related to growing up in a rural area. Life seemed simple and pure when I lived on my family's farm. I still envy that tranquility every time I visit my parents or grandparents. I imagine that persons from differing cultures show similar preference to their own types of communities. Observing how the hospice patients I visited are spending their final days reaffirmed my desire to spend my last days where I can appreciate nature and avoid the frenzied lifestyle of urban living. In addition, part of my decision to become a physician was my desire to work in a rural area and care for rural patients. Although I remain dedicated to this goal, I also acknowledge I need to learn to relate better with patients with whom I have nothing in common. I recognize that I can provide more comprehensive care in the future by making conscious efforts to establish better rapport with patients whose backgrounds are distinct from my own.

I further realize how fortunate I am to have a supportive family. Aside from a grandfather who died before I was born, I have never lost a first- or second-degree relative. I do not understand the pain of loss that Mrs. Smith must have experienced, not once, but on many occasions. Yedidia and MacGregor ${ }^{1}$ maintain that a patient's perception of death is a reflection of the broader reference that gives meaning to previous life events. ${ }^{1}$ Perhaps Mrs. Smith's previous experiences with death gave birth to an outlook that has made her own death more acceptable. By searching for themes in a patient's life, I have discovered a theme in my own life. Because I lack experience with death, I tend to deny its possibility. My choice to interview a patient with a reasonable chance of recovery might have been ironic, or it might have been a subconscious effort to avoid interaction with a dying person. Instead of focusing on end-of-life issues, I spent most of my time researching treatment options and concocting ways to persuade the patient to make what I believed to be the right choice. I now realize that the right choice is determined entirely by the patient. No other person is more aware of her medical, social, and psychological needs.

\section{Reference}

1. Yedidia MJ, MacGregor B. Confronting the prospect of dying. Reports of terminally ill patients. J Pain Symptom Manage 2001;22:807-19. 